\title{
The Effect of Lactobacillus casei on Experimental Porcine Inflammatory Bowel Disease Induced by Dextran Sodium Sulphate
}

\author{
Jan Burešl,*, Darina Kohoutová1,2, Jaroslav Květina', Věra Radochováa, Michal Pavlík ${ }^{3}$, Aleš Tichý4, \\ Stanislav Rejchrtt, Marcela Kopáčová ${ }^{1}$, Tomáš Douda ${ }^{1}$, David Vysloužil ${ }^{5}$, Jaroslav Pejchal ${ }^{5}$
}

ABSTRACT

Background: Gastrointestinal injury caused by dextran sodium sulphate (DSS) is a reliable porcine experimental model of inflammatory bowel disease (IBD). The purpose of this study was to evaluate the effect of probiotic Lactobacillus casei DN 114001 (LC) on DSS-induced experimental IBD.

Results: Eighteen female pigs (Sus scrofa f. domestica, weight $33-36 \mathrm{~kg}$, age 4-5 months) were divided into 3 groups (6 animals per group): controls with no treatment, DSS, and DSS + LC. LC was administered to overnight fasting animals in a dietary bolus in the morning on days $1-7$ ( $4.5 \times 10^{10}$ live bacteria/day). DSS was applied simultaneously on days 3-7 (0.25 g/kg/day). On day 8, the pigs were sacrificed. Histopathological score and length of crypts/glands (stomach, jejunum, ileum, transverse colon), length and width of villi (jejunum, ileum), and mitotic and apoptotic indices (jejunum, ileum, transverse colon) were assessed.

DSS increased the length of glands in the stomach, length of crypts and villi in the jejunum and ileum, and the histopathological score of gastrointestinal damage, length of crypts and mitotic activity in the transverse colon. Other changes did not achieve any statistical significance. Administration of LC reduced the length of villi in the jejunum and ileum to control levels and decreased the length of crypts in the jejunum. Conclusions: Treatment with a probiotic strain of LC significantly accelerated regeneration of the small intestine in a DSS-induced experimental porcine model of IBD.

\section{KEYWORDS}

dextran sodium sulphate; experimental inflammatory bowel disease; Lactobacillus casei DN 114001; pigs

AUTHOR AFFILIATIONS

${ }^{1}$ 2nd Department of Internal Medicine - Gastroenterology, Charles University, Faculty of Medicine in Hradec Králové, University Hospital, Hradec Králové, Czech Republic

2 The Royal Marsden NHS Foundation Trust, London, United Kingdom

${ }^{3}$ Animal Laboratory, University of Defence, Faculty of Military Health Sciences, Hradec Králové, Czech Republic

${ }^{4}$ Department of Radiobiology, University of Defence, Faculty of Military Health Sciences, Hradec Králové, Czech Republic

${ }^{5}$ Department of Toxicology and Military Pharmacy, University of Defence, Faculty of Military Health Sciences, Hradec Králové, Czech Republic

* Corresponding author: 2nd Department of Internal Medicine - Gastroenterology, Charles University Faculty of Medicine and University Hospital, Sokolská 581, 50005 Hradec Králové, Czech Republic; e-mail: bures@lfhk.cuni.cz

\section{FOOTNOTE}

Preliminary results of this study were presented as a poster at the 26th United European Gastroenterology Week, Vienna, October 20-24, 2018 (abstract published in UEG J 2018; 6, Suppl 1: A654) and Digestive Disease Week, San Diego, CA, USA, May 18-21, 2019 (abstract published in Gastroenterology 2019; 156, No 6 Suppl 1: S623-S624).

Received: 21 December 2020

Accepted: 26 February 2021

Published online: 30 July 2021

Acta Medica (Hradec Králové) 2021; 64(2): 85-90

https://doi.org/10.14712/18059694.2021.15

(c) 2021 The Authors. This is an open-access article distributed under the terms of the Creative Commons Attribution License (http://creativecommons.org/licenses/by/4.0), which permits unrestricted use, distribution, and reproduction in any medium, provided the original author and source are credited. 


\section{BACKGROUND}

The aetiology and pathogenesis of inflammatory bowel disease (IBD) comprise genetic susceptibility, various environmental factors (including infectious agents and xenobiotics), and abnormal immune response to intestinal microbiota (1). Both ulcerative colitis (UC) and Crohn's disease (CD) are associated with a reduced microbial diversity (2). Thus, the use of probiotics could be beneficial as they increase microbial diversity, which may subsequently improve the balance and function of intestinal microbiota ( 3 , 4). The possible therapeutic role of probiotics and/or synbiotics has been evaluated in several studies; however, no indisputable final conclusions were achieved $(5,6)$.

The European Crohn's and Colitis Organisation has stated that there is no evidence to suggest that probiotics are beneficial for the maintenance of remission in $C D$ (7). According to the Cochrane Database, there is insufficient evidence currently to draw any conclusion regarding the efficacy of probiotics for induction and maintenance of remission and prevention of post-operative recurrence of CD (8-10). In contrast, probiotic VSL\#3 (a mixture of eight strains, including bifidobacteria, lactobacilli and Streptococcus thermophilus) can improve therapeutic response and maintenance of remission in UC patients (11). The probiotic VSL\#3 has been shown to prevent pouchitis within the first year after surgery. According to Magro et al., after achieving remission in chronic pouchitis by treatment, VSL\#3 can maintain the remission (12). Another probiotic strain that was found possibly beneficial to maintain the remission in UC is Escherichia coli Nissle. However there is no evidence on the efficacy of other probiotics regarding UC (13). The Cochrane Database reviews stated that conventional therapy combined with a probiotic does not improve overall remission rates in patients with mild to moderate UC (14-15). The effects of antibiotics, probiotics and other interventions for treating and preventing pouchitis are uncertain (16). Further studies are indispensable so that conclusive inference on the efficacy of probiotics in $\mathrm{UC}$ and $\mathrm{CD}$ can be made (4).

The experimental model of colitis induced by dextran sodium sulphate (DSS) in mice was proposed in mid 90s (17-19). DSS-induced mucosal injury also represents a suitable and reliable experimental porcine model of IBD (20-22). Pigs can be used in various preclinical experiments due to their relatively similar gastrointestinal physiology compared to that of humans (23-24), including the porcine intestinal microbiome (25-27). In our previous projects, we studied the effect of probiotic Escherichia coli Nissle on bacteriocin production and indomethacin-induced gastrointestinal injury in experimental pigs $(28,29)$. Escherichia coli Nissle alone provided a significantly favourable trophic effect on the colonic mucosa. By contrast, indomethacin and probiotics administered together led to the worst outcome on the porcine stomach, small and large bowel ("anti-synbiotic" effect), and bacteriocin production $(28,29)$. On the other hand, lactobacilli can ameliorate indomethacin-induced intestinal injury (30). Additionally, lactobacilli possess a protective effect against DSS-induced experimental colitis in mice (31-34). The purpose of this study was to evaluate the effect of probiotic Lactobacillus casei DN 114001 (LC) on a DSS-induced experimental porcine model of IBD.

\section{METHODS}

\section{ANIMALS}

Eighteen experimental adult female pigs (Sus scrofa $f$. domestica, hybrids of Czech White and Landrace breeds; weight: $33-36 \mathrm{~kg}$, mean $34.3 \pm 1.0$; age $4-5$ months) were enrolled into the study. The animals were purchased from a certified breeder (Stepanek, Dolni Redice, Czech Republic; SHR MUHO 2050/2008/41). The pigs were housed in an accredited vivarium (temperature $21 \pm 1{ }^{\circ} \mathrm{C}, 12$ hour light/dark cycle; Faculty of Military Health Sciences, Hradec Kralove, Czech Republic). All animals were fed with standard assorted A1 food (Ryhos, Novy Rychnov, Czech Republic) of equal amounts twice a day and had free access to drinking water. The acclimatization period was 21 days before the experiment.

The study was conducted in accordance with the Basic \& Clinical Pharmacology \& Toxicology policy for experimental and clinical studies (35). Animals were held and treated in conformity with the European Convention for the Protection of Vertebrate Animals (36) and in accordance with the ARRIVE Guidelines (37).

\section{STUDY DESIGN}

The animals were divided into 3 groups: controls with no treatment $(n=6)$, DSS $(n=6)$ and DSS + LC $(n=6)$. LC was administrated to overnight fasting animals in a single dietary bolus in the morning on days 1-7 $\left(4.5 \times 10^{10}\right.$ live bacteria/day). DSS (molecular weight $40 \mathrm{kDa}$; purchased from Sigma-Aldrich, St. Louis, MO, USA) was applied simultaneously in another dietary bolus on days 3-7 (0.25 g/kg/day). On day 8 (after 24 hours of fasting), the pigs were anaesthetized (intramuscular ketamine, Narkamon, Bioveta, Ivanovice na Hane, Czech Republic, dose $20 \mathrm{mg} / \mathrm{kg}$; and azaperone, Stresnil, Jansen Pharmaceutica, Beerse, Belgium, dose $2 \mathrm{mg} / \mathrm{kg}$ ), and sacrificed by exsanguination. Immediate autopsy was performed and specimens for structural and morphometric analysis were collected, including the stomach (middle part of the gastric body), and the middle parts of the jejunum, ileum and transverse colon. The samples were immediately fixed with $10 \%$ neutral buffered formalin (Bamed, Ceske Budejovice, Czech Republic). There were no adverse events in any experimental group.

\section{STAINING OF SAMPLES}

The formalin-fixed samples were routinely processed. This included dehydration, embedding into paraffin (Paramix, Holice, Czech Republic), preparation of $5 \mu \mathrm{m}$ thick tissue sections using microtome model SM2000 R (Leica, Wetzlar, Germany), rehydration, staining with haematoxylin-eosin (Sigma-Aldrich), final dehydration, and mounting into an aqueous-free mounting medium DPX (Sigma-Aldrich). 


\section{HISTOPATHOLOGICAL SCORE}

Stained samples were evaluated using a BX-51 microscope (Olympus, Tokyo, Japan). The histopathology score (from 0 to 11) was measured according to Appleyard and Wallace by summation of scores for loss of mucosal architecture, cellular infiltration, muscle thickening, crypt abscess formation, and goblet cell depletion (Table 1) (38). Evaluation of all samples was performed by one person.

Tab. 1 Histopathology score of gastrointestinal damage (ref. 38).

\begin{tabular}{|l|l|}
\hline \multicolumn{1}{|c|}{ Parameter } & \multicolumn{1}{c|}{ Score } \\
\hline loss of mucosal architecture & $\begin{array}{l}0,1,2,3 \text { (absent, mild, moderate, } \\
\text { severe) }\end{array}$ \\
\hline cellular infiltration & $\begin{array}{l}0,1,2,3 \text { (absent, mild, moderate, } \\
\text { extensive) }\end{array}$ \\
\hline muscle thickening & $\begin{array}{l}0,1,2,3 \text { (absent, mild, moderate, } \\
\text { extensive) }\end{array}$ \\
\hline crypt abscess formation & 0 or 1 (absent or present) \\
\hline goblet cell depletion & 0 or 1 (absent or present) \\
\hline
\end{tabular}

\section{LENGTH OF CRYPTS AND GLANDS}

\section{AND LENGTH AND WIDTH OF VILLI}

The length of crypts/glands (all segments) and length and width of villi (small intestine only) were assessed by BX-51 microscope equipped with image analysis software ImagePro plus 7 (Media Cybernetics, Rockville, MD, USA). For this analysis, 20 randomly selected glands and 20 randomly selected crypts and villi per animal were measured under $80 \times$ and $200 \times$ magnification, respectively.

\section{EVALUATION OF MITOTIC}

\section{AND APOPTOTIC ACTIVITIES}

In crypts, mitotic and apoptotic activity were measured under 400 $\times$ magnification and published as apoptotic and mitotic indices. The definition of an apoptotic cell and calculation of both indices were according to previous work done by Pejchal et al. (39).

\section{STATISTICS}

Kruskal-Wallis test with multiple pairwise comparisons was used for statistical analysis (IBM SPSS Statistics, version 24; IBM Corp., Armonk, NY, USA). Differences were considered significant when $\mathrm{p}<0.05$.

\section{ETHICS APPROVAL}

The Project was approved by the Institutional Review Board of the Animal Care Committee of the University of Defence (Record Number 14922006), Faculty of Military Health Services, Hradec Králové, Czech Republic.

\section{RESULTS}

DSS treatment increased the length of gastric glands by $12 \%$ ( $p<0.001)$, the length of villi and crypts in the jejunum by $10 \%(\mathrm{p}=0.023)$ and $41 \%(\mathrm{p}<0.001)$ respectively, the length of villi and crypts in the ileum by $16 \%(\mathrm{p}=0.047)$ and $23 \%(p<0.001)$ respectively, and the histopathological score in the colon from 0 (controls) to $3.80 \pm 1.3(\mathrm{p}=0.007)$, which was associated with increased length of crypts and mitotic activity by $57 \%$ and $158 \%$ respectively (Table 2 ). Administration of LC reduced the length of villi in the jejunum and ileum to control levels. It also decreased the length of crypts in the jejunum by $13 \%$ when compared with DSS-treated animals (Table 2). Minor to moderate inflammatory changes were found over the small and large intestine (Figures 1-3).

Tab. 2 Average values of histopathological score, morphometric parameters and apoptotic and mitotic indices in the stomach, jejunum, ileum, and transverse colon (mean \pm SEM).

\begin{tabular}{|c|c|c|c|c|}
\hline & & Controls & DSS & DSS + LC \\
\hline & Stomach & & & \\
\hline $\begin{array}{l}\text { Histopatho- } \\
\text { logical score }\end{array}$ & & $0 \pm 0$ & $0 \pm 0$ & $0 \pm 0$ \\
\hline \multirow[t]{2}{*}{ glands } & length $(\mu \mathrm{m})$ & $1000 \pm 28$ & $1118 \pm 19 \dagger$ & $1102 \pm 17 \dagger$ \\
\hline & Jejunum & & & \\
\hline $\begin{array}{l}\text { Histopatho- } \\
\text { logical score }\end{array}$ & & $0 \pm 0$ & $0.6 \pm 0.4$ & $0.4 \pm 0.4$ \\
\hline \multirow[t]{2}{*}{ villi } & length $(\mu \mathrm{m})$ & $293 \pm 14$ & $308 \pm 13 \dagger$ & $282 \pm 16 \neq$ \\
\hline & width $(\mu \mathrm{m})$ & $196 \pm 11$ & $191 \pm 10$ & $189 \pm 10$ \\
\hline \multirow[t]{4}{*}{ crypts } & length $(\mu \mathrm{m})$ & $312 \pm 9$ & $440 \pm 13 \dagger$ & $385 \pm 15$ † \\
\hline & apoptotic index (\%) & $0.4 \pm 0.1$ & $0.3 \pm 0.0$ & $0.3 \pm 0.1$ \\
\hline & mitotic index (\%) & $0.7 \pm 0.2$ & $0.8 \pm 0.3$ & $0.7 \pm 0.3$ \\
\hline & Ileum & & & \\
\hline $\begin{array}{l}\text { Histopatho- } \\
\text { logical score }\end{array}$ & & $0 \pm 0$ & $0.2 \pm 0.4$ & $0.6 \pm 0.7$ \\
\hline \multirow[t]{2}{*}{ villi } & length $(\mu \mathrm{m})$ & $251 \pm 13$ & $292 \pm 19 \dagger$ & $245 \pm 14 \neq$ \\
\hline & width $(\mu \mathrm{m})$ & $186 \pm 9$ & $187 \pm 12$ & $195 \pm 12$ \\
\hline \multirow[t]{4}{*}{ crypts } & length $(\mu \mathrm{m})$ & $282 \pm 9$ & $347 \pm 12 \dagger$ & $323 \pm 11 \dagger$ \\
\hline & apoptotic index (\%) & $0.4 \pm 0.2$ & $0.4 \pm 0.2$ & $0.3 \pm 0.1$ \\
\hline & mitotic index (\%) & $1.3 \pm 0.6$ & $1.0 \pm 0.3$ & $1.1 \pm 0.3$ \\
\hline & Transverse colon & & & \\
\hline $\begin{array}{l}\text { Histopatho- } \\
\text { logical score }\end{array}$ & & $0 \pm 0$ & $3.8 \pm 1.3 \dagger$ & $3.6 \pm 1.2 \dagger$ \\
\hline \multirow[t]{3}{*}{ crypts } & length $(\mu \mathrm{m})$ & $421 \pm 10$ & $660 \pm 19 \dagger$ & $660 \pm 18 \dagger$ \\
\hline & apoptotic index (\%) & $1.0 \pm 0.4$ & $0.8 \pm 0.3$ & $0.7 \pm 0.4$ \\
\hline & mitotic index (\%) & $1.2 \pm 0.3$ & $3.1 \pm 1.6 \dagger$ & $2.4 \pm 1.0 \dagger$ \\
\hline
\end{tabular}

† Significant differences between control and DSS or control and DSS + LC groups: $p \leq 0.05$.

‡ Significant differences between DSS and DSS + LC groups: $p \leq 0.05$. 


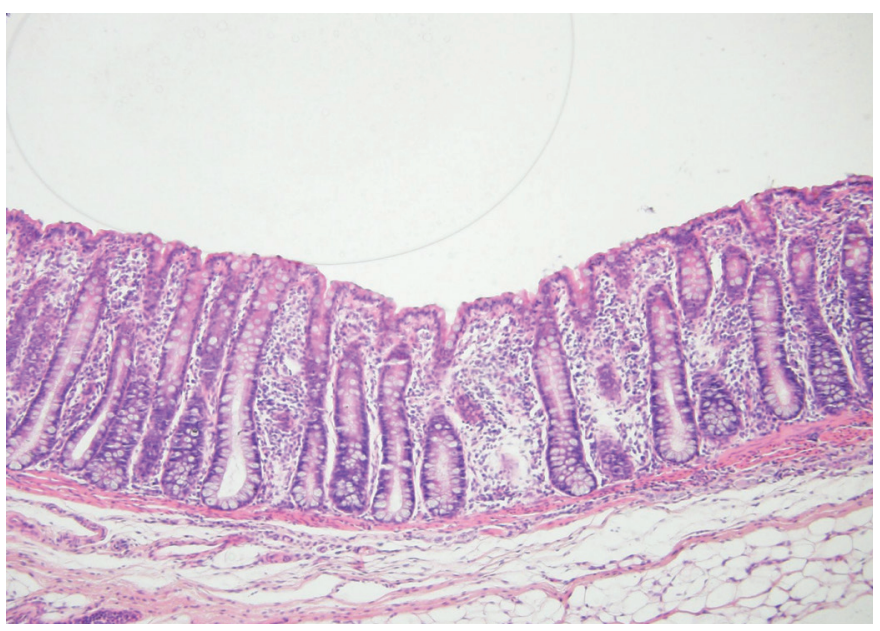

Fig. 1 Control sample of the porcine transverse colon stained with haematoxylin-eosin at 100 fold original magnification. No pathology can be observed.

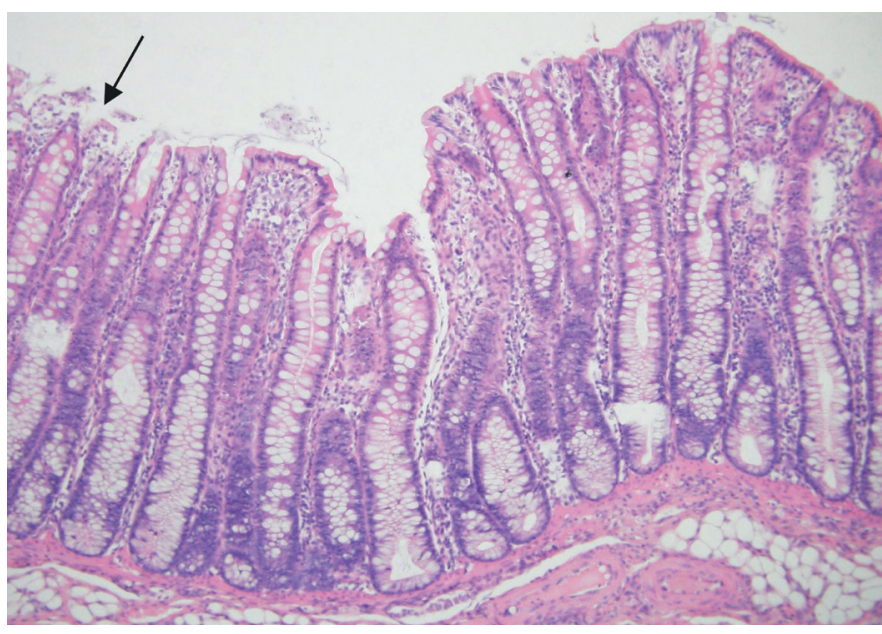

Fig. 2 DSS-treated sample of the porcine transverse colon stained with haematoxylin-eosin at 100 fold original magnification. Slight mucosal oedema with acute inflammatory infiltrate and prolonged crypts can be observed. Arrow indicates mucosal erosion.

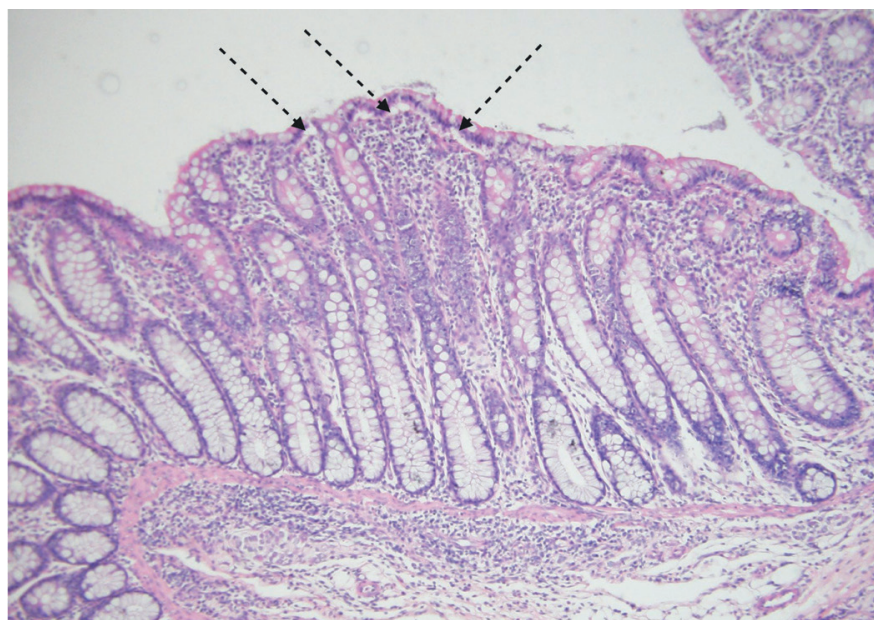

Fig. 3 DSS and Lactobacillus casei treated sample of the porcine transverse colon stained with haematoxylin-eosin at 100 fold original magnification. Slight subepithelial (dashed arrows) and mucosal oedema with an in inflammatory infiltrate and prolonged crypts can be observed.

\section{DISCUSSION}

Our current study brought new important insight into experimental IBD. To our best knowledge, this is the first study of LC in a DSS-induced porcine experimental model of IBD. DSS is able to induce not only colonic but also small intestinal injury. The lengths of jejunal villi and small intestinal and colonic crypts were significantly taller in the DSS group compared to controls and the DSS+LC group. The histopathology score and mitotic index were increased significantly only in the porcine colon.

Knowledge on a number of species of the genus Lactobacillus has broadened considerably during the past 15 years. More than two hundred species are currently recognized (40). Some probiotic lactobacilli have been used for decades, and several species are clearly characterized by their anti-inflammatory effect (41-43). Nonetheless molecular mechanisms underlying the probiotic impact have as yet not been fully understood (40). An ameliorating and/or preventive impact of lactobacilli in murine DDS-induced colitis has been found in several studies (44-47). This effect may be explained by inhibition of excessive activation of the NF- $\kappa$ B pathway $(44,45)$, suppression of TNF- $\alpha$-mediated apoptosis of intestinal epithelial cells (48), by activation of epidermal growth factor receptor (49), down-regulation of neutrophilic infiltration (in the case of incomplete tolllike receptor 4 complex signalling) (46), or by down-regulation of $\mathrm{T}$ follicular helper cells (50).

Even a lysate of non-living probiotic lactobacilli can prevent severe inflammation by improving the integrity of the intestinal barrier, and/or by modulation of the murine gut microenvironment (51-53). Lactobacillus casei decreases caecal and colonic inflammatory scores $(41,47)$. It can also prevent body weight loss in experimental animals in DSS-induced murine colitis $(47,54)$.

Vetuschi et al. (55) and Araki et al. (56) found increased apoptosis and decreased proliferation of epithelial cells that might lead to a breakdown of the epithelial barrier function. The authors concluded that this could facilitate the mucosal invasion of intraluminal microorganisms in DSS-induced murine colitis (56). Chae et al. found that lactic acid bacteria can reduce both colitis-induced and NF- $\kappa \mathrm{B}$-mediated apoptosis of intestinal epithelial cells in mice (48). We did not find any significant difference in apoptosis in our current porcine study. However, the mitotic index of the colonic mucosa was significantly higher in the DSS group. It is surprising that the apoptotic index did not change in any segment of the investigated gastrointestinal tract. However, apoptosis is a very complex event which is regulated by both pro-apoptotic and anti-apoptotic components. Survivin, an anti-apoptotic protein has been studied extensively in cancer patients, but little knowledge exists about this inhibitor of apoptosis in IBD patients. It has been reported that levels of survivin are increased in lamina propria T-cells in patients with CD, which leads to an anti-apoptotic effect of the $\mathrm{T}$ cells (57). Mennigen et al. found that the probiotic mixture VSL\#3 (also containing lactobacilli) protects the epithelial barrier by maintaining tight junction protein expression and preventing apoptosis in a murine model of colitis (58). Other studies with VSL\#3 
in murine DSS-induced colitis found also a beneficial effect of probiotics improving ileal microbiota composition $(59,60)$. The impact of DSS on the entire gastrointestinal tract depends on three variables: molecular weight of DSS, daily dose and cumulative dose of DSS. In our current study, only minor to moderate inflammatory changes were found over the small and large intestine. Differing doses of DSS have been recommended (from 0.25 to $1 \mathrm{~g} / \mathrm{kg} /$ day) to induce experimental IBD. We intentionally decided for a lower dose. Experimental animals (mouse, rat, pig) may express different sensitivity to DSS. In addition, particular batches of DSS may differ in their grade of toxicity. That is why we recommend conducting preliminary testing of a particular batch of DSS on control animals so that the dose can be adjusted accordingly (our unpublished data).

We are aware of possible limits of our current study. The project was designed as an acute one, lasting eight days only. Longer duration could reveal additional findings, especially possible apoptotic changes of the intestinal epithelial cells.

Probiotics may have a positive impact on intestinal inflammatory changes through their interaction directly with the immune system or indirectly through the modulation of gut microbiota (61). Further studies, both experimental and clinical, are needed to understand this process in detail. Only thus, possible clinical applications may be possible.

\section{CONCLUSIONS}

Treatment with the probiotic strain LC significantly accelerated regeneration of the small intestine in a DSS-induced experimental porcine model of IBD.

\section{COMPETING INTERESTS}

The authors declare that they have no competing interests.

\section{FUNDING}

The study was supported by the Research Project MH CZ DRO (UHHK, 00179906) and by the academic Research Project PROGRES Q40-15 from Charles University. The funders had no role in study design and collection, analysis, and interpretation of data, or preparation of the manuscript.

\section{ACKNOWLEDGEMENTS}

Probiotic Lactobacillus casei DN 114001 was a kind gift from Professor Helena Tlaskalova-Hogenova, MD, DSc (Institute of Microbiology of the Czech Academy of Sciences, Praha, Czech Republic).

The authors are grateful to Ian McColl MD, PhD for assistance with the manuscript.

\section{REFERENCES}

1. Larabi A, Barnich N, Nguyen HTT. New insights into the interplay between autophagy, gut microbiota and inflammatory responses in IBD. Autophagy 2019: 1-14.

2. de Vos WM, de Vos EAJ. Role of the intestinal microbiome in health and disease: from correlation to causation. Nutr Rev 2012; 70: S45-56.

3. Venema K, Do Carmo AP. Future possibilities for pro- and prebiotics: Is the sky the limit? In: Venema K, Do Carmo AP, Eds. Probiotics and Prebiotics. Current Research and Future Trends. Norfolk: Caister Academic Press, 2015: 489-93.

4. Parker EA, Roy T, D'Adamo CR, Wieland LS. Probiotics and gastrointestinal conditions: An overview of evidence from the Cochrane Collaboration. Nutrition 2018; 45: 125-34.

5. Kruis W, Fric P, Pokrotnieks J, Lukas M, et al. Maintaining remission of ulcerative colitis with the probiotic Escherichia coli Nissle 1917 is as effective as with standard mesalazine. Gut 2004; 53: 1617-23.

6. Derwa Y, Gracie DJ, Hamlin PJ, Ford AC. Systematic review with meta-analysis: the fficacy of probiotics in inflammatory bowel disease. Aliment Pharmacol Ther 2017; 46: 389-400.

7. Gomollón F, Dignass A, Annese V, et al. 3rd European Evidence-based Consensus on the Diagnosis and Management of Crohn's Disease 2016: Part 1: Diagnosis and medical management. J Crohns Colitis 2017; 11: 3-25.

8. Butterworth AD, Thomas AG, Akobeng AK. Probiotics for induction of remission in Crohn's disease. Cochrane Database Syst Rev 2008; CD006634.

9. Doherty G, Bennett G, Patil S, Cheifetz A, Moss AC. Interventions for prevention of post-operative recurrence of Crohn's disease. Cochrane Database Syst Rev 2009; CD006873.

10. Rolfe VE, Fortun PJ, Hawkey CJ, Bath-Hextall F. Probiotics for maintenance of remission in Crohn's disease. Cochrane Database Syst Rev 2006; CD004826.

11. Danese S, Fiocchi C. Ulcerative colitis. N Engl J Med 2011; 365: 1713-25.

12. Magro F, Gionchetti P, Eliakim R, et al. Third European Evidence-based Consensus on Diagnosis and Management of Ulcerative Colitis. Part 1: Definitions, diagnosis, extra-intestinal manifestations, pregnancy, cancer surveillance, surgery, and ileo-anal pouch disorders. J Crohns Colitis 2017; 11: 649-70.

13. Harbord M, Eliakim R, Bettenworth D, et al. European Evidence-based Consensus on Diagnosis and Management of Ulcerative Colitis. Part 2: Current management. J Crohns Colitis 2017; 11: 1512.

14. Mallon P, McKay D, Kirk S, Gardiner K. Probiotics for induction of remission in ulcerative colitis. Cochrane Database Syst Rev 2007; CD005573.

15. Naidoo K, Gordon M, Fagbemi AO, Thomas AG, Akobeng AK. Probiotics for maintenance of remission in ulcerative colitis. Cochrane Database Syst Rev 2011; CD007443.

16. Nguyen N, Zhang B, Holubar SD, Pardi DS, Singh S. Treatment and prevention of pouchitis after ileal pouch-anal anastomosis for chronic ulcerative colitis. Cochrane Database Syst Rev 2019; CD001176.

17. Tamaru T, Kobayashi H, Kishimoto S, Kajiyama G, Shimamoto F, Brown WR. Histochemical study of colonic cancer in experimental colitis of rats. Dig Dis Sci 1993; 38: 529-37.

18. Dieleman LA, Ridwan BU, Tennyson GS, Beagley KW, Bucy RP, Elson CO. Dextran sulphate sodium-induced colitis occurs in severe combined immunodeficient mice. Gastroenterology 1994; 107: 1643-52.

19. Ni J, Chen SF, Hollander D. Effects of dextran sulphate sodium on intestinal epithelial cells and intestinal lymphocytes. Gut 1996; 39: 234-41.

20. Bassaganya-Riera J, Hontecillas R. CLA and n-3 PUFA differentially modulate clinical activity and colonic PPAR-responsive gene expression in a pig model of experimental IBD. Clin Nutr 2006; 25: 454-65.

21. Lackeyram D, Young D, Kim CJ, et al. Interleukin-10 is differentially expressed in the small intestine and the colon experiencing chronic inflammation and ulcerative colitis induced by dextran sodium sulphate in young pigs. Physiol Res 2017; 66: 147-62.

22. Xiao Y, Yan H, Diao H, et al. Early Gut Microbiota Intervention Suppresses DSS-Induced Inflammatory Responses by Deactivating TLR/ NLR Signalling in Pigs. Sci Rep 2017; 7: 3224.

23. Kararli TT. Comparison of the gastrointestinal anatomy, physiology, and biochemistry of humans and commonly used laboratory animals. Biopharm Drug Dispos 1995; 16: 351-80.

24. Suenderhauf C, Parrott N. A physiologically based pharmacokinetic model of the minipig: data compilation and model implementation. Pharm Res 2013; 30: 1-15.

25. Ke S, Fang S, He M, Huang X, et al. Age-based dynamic changes of phylogenetic composition and interaction networks of health pig gut microbiome feeding in a uniformed condition. BMC Vet Res 2019; 15: 172 . 
26. Shin D, Chang SY, Bogere P, et al. Beneficial roles of probiotics on the modulation of gut microbiota and immune response in pigs. PLoS ONE 2019; 14: e0220843.

27. Wang X, Tsai T, Deng F, et al. Longitudinal investigation of the swine gut microbiome from birth to market reveals stage and growth performance associated bacteria. Microbiome 2019; 7: 109.

28. Bures J, Pejchal J, Kvetina J, et al. Morphometric analysis of the porcine gastrointestinal tract in a 10-day high-dose indomethacin administration with or without probiotic bacteria Escherichia coli Nissle 1917. Hum Exp Toxicol 2011; 30: 1955-62.

29. Bures J, Smajs D, Kvetina J, et al. Bacteriocinogeny in experimental pigs treated with indomethacin and Escherichia coli Nissle. World J Gastroenterol 2011; 17: 609-17.

30. Santiago-López L, Hernández-Mendoza A, Vallejo-Cordoba B, Mata-Haro V, Wall-Medrano A, González-Córdova AF. Milk fermented with Lactobacillus fermentum ameliorates indomethacin-induced intestinal inflammation: An exploratory study. Nutrients 2019; 11: e1610.

31. Osaka T, Moriyama E, Arai S, et al. Meta-analysis of fecal microbiota and metabolites in experimental colitic mice during the inflammatory and healing phases. Nutrients 2017; 9: e1329.

32. Zhang Y, Zhao X, Zhu Y, Ma J, Ma H, Zhang H. Probiotic mixture protects dextran sulphate sodium-induced colitis by altering tight junction protein expressions and increasing tregs. Mediators Inflamm 2018; 2018 : 9416391.

33. Wang G, Liu Y, Lu Z, et al. The ameliorative effect of a Lactobacillus strain with good adhesion ability against dextran sulphate sodium-induced murine colitis. Food Funct 2019; 10: 397-409.

34. Wasilewska E, Zlotkowska D, Wroblewska B. Yogurt starter cultures of Streptococcus thermophilus and Lactobacillus bulgaricus ameliorate symptoms and modulate the immune response in a mouse model of dextran sulphate sodium-induced colitis. J Dairy Sci 2019; 102: 37-53.

35. Tveden-Nyborg P, Bergmann TK, Lykkesfeldt J. Basic \& clinical pharmacology \& toxicology policy for experimental and clinical studies. Basic Clin Pharmacol Toxicol 2018; 123: 233-5.

36. Explanatory Report on the European Convention for the Protection of Vertebrate Animals Used for Experimental and Other Scientific Purposes (ETS 123). Strasbourg: Council of Europe, 2009.

37. Kilkenny C, Browne WJ, Cuthill IC, Emerson M, Altman DG. Improving bioscience research reporting: the ARRIVE guidelines for reporting animal research. PLoS Biol 2010; 8: e1000412.

38. Appleyard CB, Wallace JL. Reactivation of hapten-induced colitis and its prevention by anti-inflammatory drugs. Am J Physiol 1995; 269: G119-125.

39. Pejchal J, Sinkorova Z, Tichy A, et al. Epidermal Growth Factor Attenuates Delayed Ionizing Radiation-Induced Tissue Damage in Bone Marrow Transplanted Mice. Radiat Res 2016; 186: 264-74.

40. Venema K, Meijerink M. Lactobacilli as probiotics: Discovering new functional aspects and target sites. In: Venema K, Do Carmo AP, Eds. Probiotics and Prebiotics. Current Research and Future Trends. Norfolk: Caister Academic Press, 2015: 29-41.

41. Rochat T, Bermúdez-Humarán L, Gratadoux JJ, et al. Anti-inflammatory effects of Lactobacillus casei BL23 producing or not a manganese-dependant catalase on DSS-induced colitis in mice. Microb Cell Fact 2007; 6: 22 .

42. Watterlot L, Rochat T, Sokol H, et al. Intragastric administration of a superoxide dismutase-producing recombinant Lactobacillus casei BL23 strain attenuates DSS colitis in mice. Int J Food Microbiol 2010; 144: 35-41.

43. Wong CC, Zhang L, Li ZJ, et al. Protective effects of cathelicidin-encoding Lactococcus lactis in murine ulcerative colitis. J Gastroenterol Hepatol 2012; 27: 1205-12.

44. Yoon S-W, Lee C-H, Kim J-Y, Kim J-Y, Sung M-H, Poo H. Lactobacillus casei secreting alpha-MSH induces the therapeutic effect on DSS-in- duced acute colitis in Balb/c mice. J Microbiol Biotechnol 2008; 18: 1975-83.

45. Qiu ZB, Chen J, Chen JJ, et al. Effect of recombinant Lactobacillus casei expressing interleukin-10 in dextran sulphate sodium-induced colitis mice. J Dig Dis 2013; 14: 76-83.

46. Chung YW, Choi JH, Oh T-Y, Eun CS, Han DS. Lactobacillus casei prevents the development of dextran sulphate sodium-induced colitis in Toll-like receptor 4 mutant mice. Clin Exp Immunol 2008; 151: 182-9.

47. Kokesova A, Frolova L, Kverka M, et al. Oral administration of probiotic bacteria (E. coli Nissle, E. coli O83, Lactobacillus casei) influences the severity of dextran sodium sulphate-induced colitis in BALB/c mice. Folia Microbiol (Praha) 2006; 51:478-84.

48. Chae JM, Chang MH, Heo W, et al. LB-9, novel probiotic lactic acid bacteria, ameliorates dextran sodium sulphate-induced colitis in mice by inhibiting TNF- $\alpha$-mediated apoptosis of intestinal epithelial cells. J Med Food 2019; 22: 271-6.

49. Yoda K, Miyazawa K, Hosoda M, Hiramatsu M, Yan F, He F. Lactobacillus GG-fermented milk prevents DSS-induced colitis and regulates intestinal epithelial homeostasis through activation of epidermal growth factor receptor. Eur J Nutr 2014; 53: 105-15.

50. Liu X-J, Yu R, Zou K-F. Probiotic mixture VSL\#3 alleviates dextran sulphate sodium-induced colitis in mice by downregulating $\mathrm{T}$ follicular helper cells. Curr Med Sci 2019; 39: 371-8.

51. Zakostelska Z, Kverka M, Klimesova K, et al. Lysate of probiotic Lactobacillus casei DN-114 001 ameliorates colitis by strengthening the gut barrier function and changing the gut microenvironment. PLoS ONE 2011; 6: e27961.

52. Sang L-X, Chang B, Dai C, Gao N, Liu W-X, Jiang M. Heat-killed VSL\#3 ameliorates dextran sulphate sodium (DSS)-induced acute experimental colitis in rats. Int J Mol Sci 2013; 15: 15-28.

53. Sang L-X, Chang B, Wang B-Y, Liu W-X, Jiang M. Live and heat-killed probiotic: effects on chronic experimental colitis induced by dextran sulphate sodium (DSS) in rats. Int J Clin Exp Med 2015; 8: 20072-8.

54. Herías MV, Koninkx JFJG, Vos JG, Huis in't Veld JHJ, van Dijk JE. Probiotic effects of Lactobacillus casei on DSS-induced ulcerative colitis in mice. Int J Food Microbiol 2005; 103: 143-55.

55. Vetuschi A, Latella G, Sferra R, Caprilli R, Gaudio E. Increased proliferation and apoptosis of colonic epithelial cells in dextran sulphate sodium-induced colitis in rats. Dig Dis Sci 2002; 47: 1447-57.

56. Araki Y, Mukaisyo K, Sugihara H, Fujiyama Y, Hattori T. Increased apoptosis and decreased proliferation of colonic epithelium in dextran sulphate sodium-induced colitis in mice. Oncol Rep 2010; 24: 869-74.

57. de Souza HSP, West GA, Rebert N, de la Motte C, Drazba J, Fiocchi C. Increased levels of survivin, via association with heat shock protein 90, in mucosal T cells from patients with Crohn's disease. Gastroenterology 2012; 143: 1017-26.e9.

58. Mennigen R, Nolte K, Rijcken E, et al. Probiotic mixture VSL\#3 protects the epithelial barrier by maintaining tight junction protein expression and preventing apoptosis in a murine model of colitis. Am J Physiol Gastrointest Liver Physiol 2009; 296: G1140-9.

59. Bassaganya-Riera J, Viladomiu M, Pedragosa M, De Simone C, Carbo A, Shaykhutdinov R, et al. Probiotic bacteria produce conjugated linoleic acid locally in the gut that targets macrophage PPAR $\gamma$ to suppress colitis. PLoS ONE 2012; 7: e31238.

60. Mar JS, Nagalingam NA, Song Y, Onizawa M, Lee JW, Lynch SV. Amelioration of DSS-induced murine colitis by VSL\#3 supplementation is primarily associated with changes in ileal microbiota composition. Gut Microbes 2014; 5: 494-503.

61. Venema K. Functional aspects of the endogenous microbiota that benefit the host. In: Venema K, Do Carmo AP, Eds. Probiotics and Prebiotics. Current Research and Future Trends. Norfolk: Caister Academic Press, 2015: 221-33. 